\title{
Introducción al estudio de la Historia Constitucional
}

Introduction to the study of Constitutional History

\author{
Guillermo Raúl Moreno ${ }^{1}$ \\ Universidad Nacional de La Plata - Argentina
}

Revista Derechos en Acción ISSN 2525-1678/e-ISSN 2525-1686

Año 5/N 16 Invierno 2020 (21 de junio a 20 de septiembre), 867-897

DOI: https://doi.org/10.24215/25251678e447

Recibido: 22/04/2020

Aprobado: 19/06/2020

\section{Historia. Historia Constitucional, Ciencia Política y Derecho Constitucional}

\section{I.1. Historia}

A la "historia" se la ha definido de múltiples maneras desde los tiempos más lejanos, pero seguramente todas esas posibles definiciones coincidirán en que estamos en presencia de un tipo de investigación sobre hechos ocurridos en el pasado. Pues, ya desde muy antiguo el término fue utilizado como sinónimo de "narración de los hechos humanos".

El hombre, el homo sapiens (del latín, "hombre sabio" u "hombre que piensa") es de muy reciente aparición en la tierra si lo comparamos con el milagro del surgimiento de la vida en nuestro planeta.

Hace unos 3800 millones de años, determinadas moléculas se combinaron para formar estructuras más grandes y complejas

\footnotetext{
1 Profesor de Historia Constitucional en la Facultad de Ciencias Jurídicas y Sociales de la Universidad Nacional de La Plata. Contacto: guillermoraulmoreno@yahoo.com.ar (ORCID: https://orcid.org/0000-0002-6334-659X).
} 
llamadas organismos. Luego de una maravillosa transformación de miles de millones de años, apareceremos nosotros, los seres humanos (solamente 300 mil años atrás), para disfrutar de la fabulosa herencia que nos ofrece la tierra. ${ }^{2}$

Si nos comparamos con las otras especies que habitan nuestro planeta, veremos que somos extremadamente frágiles. Nuestras limitaciones son enormes: imposibilidad de una vida extrauterina durante los primeros años de vida sin ayuda de otros seres, escasa fuerza física, imposibilidad de volar o permanecer bajo el agua, etc.

Pero la sabiduría del hombre estuvo siempre en haber intuido sus flaquezas y sus limitaciones. Procurará en otros animales la fuerza que la naturaleza no le dio, y así descubrirá nuevos territorios e infinitas posibilidades de conseguir el sustento diario para él y su prole.

El hombre siempre ha sido un animal social, su espíritu gregario hizo que se uniera con otros ejemplares de su especie para el logro de fines comunes. Desde sus más remotos orígenes tuvo curiosidad de saber que había ocurrido en su comunidad antes de su propia existencia. Preguntó a sus mayores, investigó sobre vestigios que pudieron haber dejado sus antepasados, en fin, indagó sobre sus orígenes y el de su comunidad. Así nacerá la "historia".

Se suele considerar como el "padre de la historia" a Heródoto (pensador de la antigua Grecia que vivió entre los años 484 y 424 a.c.) a partir de su recordada obra "Historia" donde narraba, con cierta precisión, las guerras entre Grecia y Persia con especial atención a ciertos aspectos de los pueblos involucrados en la contienda. Continuará dicha tarea su discípulo Tucídides, pero con una cuota de mayor rigurosidad en la recolección y análisis de las fuentes.

Henri Marrou, uno de los grandes historiadores que dio el siglo XX, definió a la "historia" de una manera muy clara y

2 Ampliar en HARARI, Yuval Noah, De animales a dioses, Breve historia de la humanidad, Ros Joandomènec (trad.), Buenos Aires, Debate, 2019, 493 p. ISBN: 978-987-3752-13-1 
sencilla (hecho usual en las mentes elevadas, explicar algo complejo de manera sencilla). Para él, la historia es el conocimiento del pasado humano. ${ }^{3}$

En razón de todo lo hasta aquí expuesto, nos atrevemos a ensayar una suerte de definición general del término "historia", al que identificamos como aquella ciencia social encargada del estudio y el relato de los acontecimientos ocurridos en el pasado de la humanidad.

A esta altura podríamos preguntarnos... ¿para que sirve la historia? (si es que sirve de algo). En primer lugar, como ya lo hemos dicho anteriormente, la historia satisface la necesidad de los seres humanos de conocer el pasado de su especie y así tratar de explicar el origen del tiempo actual en el que vive. Pero además de ello, y como una especie de conclusión final, estamos convencidos que conocer el pasado nos dará una abundancia de elementos que nos permitirán desarrollar nuestro juicio y direccionar la voluntad. No olvidemos que, como en todos los órdenes de la vida, tener experiencia sobre algo, nos hará más prudentes (para una próxima vez) y más sabios (para siempre).

\section{I.2. Historia Constitucional}

Si tomamos los dos términos que componen la denominación de nuestra asignatura: "historia" y "Constitución", podría inducirnos a pensar que el contenido de la misma se refiere solo a la "historia de la Constitución". Esa mirada tendría un alcance muy limitado y desactualizado de la disciplina.

Ello es así, toda vez que la Historia Constitucional se aboca al estudio de todo el proceso histórico vinculado a la organización política e institucional de un Estado. Así, en nuestro país, podríamos dividir ese proceso histórico en dos etapas diferenciadas: la primera que se extiende desde los inicios de la conquista en América a fines del Siglo XV hasta 1853, año en

3 MARROU, Henri, El Conocimiento Histórico, Le Seuil, París, 1954, p.23. 
que se sancionó y entró en vigencia la Constitución Nacional, y una segunda etapa, desde ese año hasta nuestros días. ${ }^{4}$

En esa primera etapa podríamos incluir al estudio de: las instituciones de la dominación hispánica; el movimiento emancipador y sus fundamentos doctrinarios; las primeras autoridades patrias; todos los reglamentos, estatutos, pactos; los proyectos constitucionales; las Asambleas y Congresos convocados; las constituciones malogradas que no llegaron a entrar en vigencia ${ }^{5}$, los diferentes enfrentamientos que, desde los primeros años, postularon posiciones antagónicas sobre la forma de organizar el Estado, los caudillos, los conflictos internacionales que debimos afrontar y sus consecuencias; entre otros temas. En la segunda etapa, que comenzaría con el dictado de la Constitución Nacional en 1853, se podrían mencionar: las diferentes reformas constitucionales, los grandes pactos que terminaron de consolidar la unión nacional, las presidencias fundacionales; la federalización de Buenos Aires; el surgimiento de los primeros partidos políticos; la conquista de los derechos políticos, los gobiernos de facto, la incorporación de los instrumentos internacionales de Derechos Humanos, etc.

En fin, como se puede apreciar, nuestra materia es mucho más que "la historia de la Constitución". Esa mirada integral que hoy nos proponemos al iniciar el estudio de nuestra asignatura, nos dará herramientas para comprender, desde una perspectiva amplia e interdisciplinaria, como surgieron nuestras instituciones locales y los contextos políticos, económicos y sociales que rodearon esos acontecimientos.

Por lo tanto, entendemos a la Historia Constitucional como el estudio de todo el proceso histórico-político referido a la génesis, desarrollo y funcionamiento institucional de nuestro Estado.

4 Esta división de la materia en dos etapas fue postulada en su momento por RAVIGNANI, Emilio, Prenociones para el estudio de la historia constitucional de la República Argentina, Buenos Aires, Peuser, 1930.

5 Como lo fueron la Constitución de 1819 y la de 1826. 


\section{I.3. Ciencia Política}

La "política" es la actividad humana destinada a ordenar la vida social. ${ }^{6}$ Su origen debe ser buscado en las más lejanas y primitivas formas de convivencia humana, pues su objetivo será ordenar la vida en sociedad de los hombres.

Los pensadores griegos de la antigüedad detuvieron su atención en el estudio de la política, a la que identificaban con la organización y funcionamiento de la "polis", la ciudad-estado, (del término "polis" deriva la palabra "política”). Según Aristóteles, partiendo del instinto social del hombre, consideraba al ser humano como un "animal político", el que solo alcanzaba su plenitud en la polis. Pues, a su juicio, solo un Dios o una bestia podrían tener existencia fuera de esa realidad. ${ }^{7}$

Por su parte, la "ciencia política" se nos presenta como aquella disciplina, enrolada en las ciencias sociales, que tiene por objeto el estudio de las formas de organización y gobierno de las comunidades humanas, las instituciones, doctrinas, hechos y acontecimientos vinculados a las relaciones de poder. ${ }^{8}$

Si nos detenemos a pensar acerca de los vínculos entre la ciencia política y la historia constitucional, veremos de inmediato muchos puntos en común. No debemos olvidar que la formación institucional de la Argentina se nos presenta como el resultado de un complejo y arduo proceso histórico de marchas y contramarchas durante sus primeros cincuenta años de vida independiente. ?

Como en casi todas las naciones, en nuestro país, la reflexión sobre la política es tan antigua como los conflictos políticos

\footnotetext{
6 Ver FAYT, Carlos S, Derecho Político, 6a Edición Inalterada, Buenos Aires, Depalma, 1985, 392 p., ISBN 950-14-0277-0, T. I, p. 9.

7 ARISTÓTELES, Política, $1^{\text {a }}$ edición, Buenos Aires, Centro Editor Cultura, 2005, 240 p., ISBN 950-898-086-9, Libro I, Cap. 1, p.13.

8 FAYT, Carlos S, op. cit., p. 13.

9 Ver MORENO, Guillermo Raúl, La Asamblea del año XIII. Artigas y el surgimiento del federalismo en el Río de La Plata, Derechos En Acción, 9(9). https://doi.org/10.24215/25251678e215
} 
mismos. La crisis de legitimidad en España con la invasión napoleónica y el confinamiento del Rey Fernando VII, las guerras de independencia, los primeros estatutos, reglamentos y ensayos que intentaron organizar el nacimiento del nuevo Estado, y los largos años de disputa por la organización constitucional dieron lugar a encendidas polémicas sobre los fundamentos del orden político. $^{10}$

\section{I.4. Derecho Constitucional}

En cuanto a la definición del "derecho constitucional", no será sencillo encontrar un único concepto que abarque la posición de todos los autores que se han propuesto definirlo.

Para la doctrina clásica o tradicional, el derecho constitucional será, sin más, la disciplina jurídica referida al estudio de las constituciones. En ese sentido se pronunció uno de los primeros y más conocidos constitucionalistas de nuestro país, Joaquín V. González, en su recordada obra "Manual de la Constitución Argentina", publicada a fines del Siglo XIX. ${ }^{11}$

Un enfoque más moderno y actualizado del derecho constitucional, no podría limitarse solo al estudio de los textos constitucionales. De allí que hoy en día se lo identifique, no solo con la Constitución, sino con todo el sistema de normas y principios que deben regir a un Estado de Derecho ${ }^{12}$ y que procuren el amparo de la libertad y la dignidad de todo ser humano. ${ }^{13}$

\footnotetext{
10 LEIRA, Marcelo, ABAL MEDINA, Juan Manuel y D’ALESSANDRO, Martín, La ciencia política en Argentina: el camino de la institucionalización dentro y fuera de las aulas universitarias, Revista de Ciencia Política / Volumen 25 / № 1 / 2005 / 76 - 91.

11 GONZALEZ, Joaquín V., Manual de la Constitución Argentina, Buenos Aires, Ángel Estrada y Cia. Editores 1897, ps 15 y ss.

12 Por su parte, Bielsa define al derecho constitucional como "la parte del derecho público que regla el sistema de gobierno, la formación de los poderes públicos, su estructura y atribuciones, y las declaraciones, derechos y garantías de los habitantes". BIELSA, Rafael, Derecho Constitucional, $2^{a}$ edición aumentada, Buenos Aires, Depalma, 1954, 703 p, p. 43.

13 Como señala Linares Quintana, "El derecho constitucional es el derecho de la Constitución y de las instituciones políticas, estén o no en aquella", continúa, "si la concepción
} 
El derecho constitucional es la base de todas las demás especialidades jurídicas. El maestro Ferreyra nos invita a reflexionar sobre este punto con una interesante comparación: Si pensáramos a todo el derecho como un árbol, sus raíces serían la Constitución, su tronco sería el derecho constitucional, y las ramas que nacen de su tronco, cada una de las disciplinas jurídicas o especialidades (derecho civil, derecho penal, derecho administrativo, etc.). ${ }^{14}$

El derecho constitucional, como disciplina autónoma, comenzó a ser enseñado poco después de la aparición de las primeras constituciones escritas de finales del siglo XVIIII. ${ }^{15}$ Fue por entonces que quedaron establecidas las primeras cátedras en Italia (universidades de Ferrara, Bolonia y Parma). ${ }^{16}$

En nuestro país, la primera cátedra de derecho constitucional surgió en la Universidad de Córdoba en 1834, a cargo de Santiago Derqui (quien años más tarde, en 1860, llegará a ser presidente de la Nación). ${ }^{17}$

¿Cómo se vinculan entonces la Historia Constitucional con el Derecho Constitucional? Pues, creemos que aquella,

estricta y tradicional, que llegó a prevalecer durante muchos años, circunscribía el ámbito de la disciplina nada más que al contenido de formal de la Constitución, hoy es generalizada la idea de que el derecho constitucional rebasa ampliamente el contorne de la ley fundamental de un país...". LINARES QUINTANA, Segundo V., Tratado de la Ciencia del Derecho Constitu-

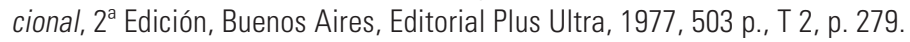

14 Ver FERREYRA, Raúl Gustavo, Fundamentos Constitucionales, $2^{\text {a }}$ edición, Buenos Aires, Ediar, 2015, 568 p., ISBN 978-950-574-3331-5, p.187.

15 Apunta Fuentes que, el estudio del derecho constitucional que se funda en el de las tradiciones de los Estados y en sus constituciones escritas es de tanta y tan elevada importancia que no solo debieran cultivarlo el publicista, el jurisconsulto y todos los que aspiran a servir a su país en la legislatura, en el orden judicial, en la administración y la enseñanza del derecho, sino todo ciudadano a quien le sea posible. FUENTES, Manuel Atanasio, Derecho constitucional filosófico, Centro de Estudios Constitucionales, Tribunal Constitucional del Perú, Lima, 2018, p. 53.

16 Ampliar en RAMELLA, Pablo A., Derecho Constitucional, $3^{\text {a }}$ edición, Buenos Aires, Depalma, 1986, 829 p., ISBN 950-43-0551-2, p. 1.

17 Ver en TANZI, Héctor José, La enseñanza del derecho constitucional en la Facultad de Buenos Aires, Academia. Revista sobre la enseñanza del derecho, Año 9, nro. 17, 2011. 
al acercarnos a los contextos político-sociales de un tiempo determinado, nos permitirá la plena comprensión del derecho constitucional vigente. ${ }^{18}$

\section{Historiografía. Historiografía argentina. Diferentes corrientes}

El término "historiografía" se identifica, en su acepción primaria, con el "arte de escribir correctamente la historia". ${ }^{19}$, es decir, con la manera en que se ha escrito la historia. De allí que se la identifique con el conjunto de técnicas y teorías relacionadas con las formas de interpretar y difundir la historia.

A su vez, la reconstrucción histórica se basará en una disciplina de suma importancia para el logro de sus objetivos como es la heurística, relacionada con las técnicas de hallazgo, acumulación y ordenamiento de testimonios, documentos y objetos materiales que den cuenta de la veracidad de los hechos pasados. La heurística perseguirá entonces, la transformación de los testimonios en fuentes históricas.

Las diferentes corrientes historiográficas surgirán a partir de las diversas interpretaciones de los hechos del pasado, como así también de las distintas, y a veces opuestas, formas de narrar o difundir ese conocimiento. Ello es así por la sencilla razón que los historiadores tienen, y han tenido siempre, diferentes posturas ideológicas a la hora de llevar adelante sus investigaciones y darlas a conocer.

En nuestro país, surgirán una gran variedad de corrientes historiográficas a partir de las distintas interpretaciones ensayadas sobre los hechos y procesos de nuestro pasado como

\footnotetext{
18 Sobre la relación entre Historia Constitucional y Derecho Constitucional, nos pareció muy enriquecedor acceder a la entrevista al Profesor Alemán E-W. BÖCKENFÖRDE, Ilevada a cabo y traducida por Benito ALAEZ CORRAL en la Revista "Historia Constitucional", n. 5, 2004. http://hc.rediris.es/05/indice.html

19 Así lo hace, al aludir a Tomás Campanella, GALLETTI, Alfredo, Historia Constitucional Argentina, $1^{a}$ edición, La Plata, Librería Editora Platense, 1987, 670 p., ISBN 950-536-027-4, T. 1, p. 33.
} 
Nación. Con el objeto de no excedernos sobre los límites de nuestro trabajo, pasaremos a mencionar a solo dos de ellas que, por sus características propias, son representativas de visiones antagónicas sobre la historia argentina. La "historia oficial" y el "revisionismo histórico". Veamos.

La "historia oficial", también llamada "liberal" o "mitrista"20 será la historia que nos ofrece una visión de nuestro pasado desde la óptica de una clase dominante, de aquellas elites representativas de los intereses de estancieros, terratenientes y grandes comerciantes. Será "oficial" ya que se enseñó, durante más de un siglo, en nuestros establecimientos de enseñanza de todos los niveles, estuvo presente en discursos y en actos oficiales, sus próceres son reconocidos por sus nombres en ciudades, calles, avenidas y plazas públicas de todo el país. Tuvo, en general, una concepción elitista y antipopular, posó su mirada (de admiración) en Europa y dio la espalda a la Argentina profunda y a sus verdaderas realidades. Desde esta concepción, los caudillos y lo que ellos representaban (las clases populares) significaron atraso, ignorancia y barbarie.

Como fiel exponente de la "historia oficial" podemos nombrar a Bartolomé Mitre (1821-1906), a quien se lo identifica con el nacimiento de esta corriente historiográfica (de allí que también se la conozca como "historia mitrista"). Sus dos obras más conocidas darán el puntapié inicial para esta corriente: "Historia de Belgrano y la independencia argentina" (publicada por primera vez en su versión completa en 1876) e "Historia de San Martín y la emancipación sudamericana" (1877). Asimismo, se puede mencionar como otro autor representativo de la "historia oficial" a Vicente Fidel López (1815-1903), quien publicó, entre otras obras, "Introducción a la historia de la revolución argentina" (1861) e "Historia de la República Argentina" (de 10 tomos, entre 1883 y 1893).

20 En este tema acudimos al trabajo de GALASSO, Norberto, De la historia oficial al revisionismo rosista. Corrientes historiográficas en Argentina, publicado en Cuadernos para la otra historia, Centro Cultural Enrique Santos Discépolo, Buenos Aires, 2004. 
En contraposición a la historia oficial, el "revisionismo histórico" aportará un discurso y una visión nacionalista y popular de la historia argentina. Destacará las figuras de los caudillos y la importancia del federalismo en las luchas civiles por la organización nacional. El surgimiento de esta corriente historiográfica llegará de la mano de algunos autores que, si bien enrolados en la historia oficial, tuvieron algunas inquietudes nacionalistas en sus investigaciones. Es el caso, por ejemplo, de Adolfo Saldías (1850/1914), quien se dedicó a estudiar la época de Rosas. ${ }^{21}$ Como resultado de esas investigaciones publicó su obra "Historia de la Confederación Argentina", la que tendrá una nueva visión sobre aquel período histórico. Así, Saldías dejará el camino allanado para que luego otros autores continúen con lo que luego se conoció como el "revisionismo histórico". Dentro de esta corriente historiográfica se suelen mencionar a Ernesto Palacio (1900-1979); Raúl Scalabrini Ortiz (1898-1959); Arturo Jauretche (1901-1974); José María Rosa (1906-1991), entre otros.

\section{El Constitucionalismo. Concepto. Postulados. Etapas}

\section{III.1. El Constitucionalismo}

Compartimos la opinión que identifica al "constitucionalismo" con el proceso histórico a través del cual se van incorporando a las leyes supremas de los Estados disposiciones tendientes a proteger los derechos fundamentales del ser humano y limitar razonablemente el poder público. ${ }^{22}$

\footnotetext{
21 Saldías logró acceder para sus investigaciones al archivo personal de Rosas, el que luego de su muerte, quedara en la casa de su hija Manuelita en la ciudad de Londres. Nos cuenta José María Rosa, al escribir el prólogo de la edición de la Historia de la Confederación de Adolfo Saldías de 1967 (Editorial Juan Carlos Granda) que "la noche de Caseros, la gran preocupación del vencido había sido salvar sus papeles, como si comprendiera que los vencedores los darían fuego para rehacer la historia con absoluta impunidad. En varios cajones los hizo llevar -su único tesoro- a la legación inglesa de la calle Defensa, y de allí al Conflic, donde marchó al exilio. Había cuidado esos papeles con veneración...". SALDIAS, Adolfo, Historia de la Confederación Argentina, Editorial Juan Carlos Granda, Buenos Aires, 1967, T. 1, p. XXII. 22 En este tema (el constitucionalismo) nos ayudó a pensar la obra del profesor Adolfo Gabino Ziulu, a quien, agradecidos, recurrimos para el desarrollo y análisis que aquí efectuamos.
} 
El constitucionalismo (o movimiento constitucionalista) surgirá a partir del Siglo XVIII, y tendrá entre sus objetivos y postulados: establecer en cada Estado un documento normativo escrito (la Constitución), con supremacía jurídica, que organice el funcionamiento racional de los poderes y a la vez reconozca y tutele los derechos y garantías de sus habitantes.

Como todo proceso histórico, atravesó distintas etapas a lo largo de su evolución en el tiempo. Hay quienes sostienen que el constitucionalismo comprende toda la historia de la humanidad, ya que no deja de reflejar la verdadera historia del hombre en su lucha por la libertad.

Los distintos períodos en la evolución del constitucionalismo pueden ser resumidos en las siguientes etapas:

1) Antecedentes

2) Constitucionalismo liberal

3) Difusión del constitucionalismo liberal

4) Crisis del constitucionalismo liberal

5) Constitucionalismo social

6) Constitucionalismo actual.

\section{1) Antecedentes}

Esta etapa abarca el extenso período anterior al advenimiento de las primeras grandes constituciones de finales del siglo XVIII.

Allí encontraremos las primeras e incipientes normas de organización de la antigüedad (como el "Código de Hammurabi" 23 del año 1750 a.c., o las "Leyes de Manú" ${ }^{24}$, siglo II a.c.).

\footnotetext{
ZIULU, Adolfo Gabino, Derecho Constitucional, 1ª edición, Buenos Aires, Abeledo-Perrot, 2014, 944 p., ISBN 978-950-20-2585-8.

23 Fue un conjunto de normas, las más antiguas que se han encontrado, y llevan el nombre del Rey de Babilonia que mandó a dictar el código.

24 Texto de la antigua India con algunas reglas de conducta que debían ser aplicados por los individuos.
} 
También ubicaremos en este período algunos documentos aparecidos durante el feudalismo, como los "fueros españoles" 25 o la "Carta Magna". Esta última, rubricada por el Rey Juan sin Tierra en Inglaterra en el año 1215, y que de alguna manera limitó ciertas potestades del Monarca (en especial la de crear impuestos sin el consentimiento de los barones y los eclesiásticos), adquirió tal importancia, que el término comenzó a ser utilizado como sinónimo de "constitución".

Mas tarde, aparecerán dos conocidos documentos en el Siglo XVII: el Agreement of the People o "Pacto popular"26 (1647) $\mathrm{y}$ el Instrument of Government o "instrumento de Gobierno"27 (1653), importantes antecedentes del constitucionalismo norteamericano.

\section{2) Constitucionalismo liberal}

Surgió en la segunda mitad del Siglo XVIII, a partir de las grandes revoluciones de la época: la Norteamericana de 1776 y la Francesa de 1789. Con él quedarán establecidos los cimientos del Estado constitucional.

Este periodo dejará como legado la necesidad del pueblo, en tanto titular de la soberanía, de darse una Constitución, con jerarquía de Ley Suprema, escrita, codificada y sistémica.

Comentando sobre las características del constitucionalismo liberal, también llamado "constitucionalismo clásico", tuvimos

\footnotetext{
25 Los fueros constituían estatutos jurídicos otorgados por el Rey a un grupo de vasallos. De alguna manera representaron las primeras limitaciones al poder real de los monarcas. Se pueden mencionar los fueros de León (1020); Burgos (1073); de Aragón (1283), entre otros.

26 Elaborado en Inglaterra, buscaba "proteger mediante un documento escrito que fuera norma suprema ("paramount law"), los derechos y libertades fundamentales de los ingleses, así como el entramado institucional y democrático en el que podrían hacerse valer". Ampliar en CUEVA FERNANDEZ, Ricardo, Los "agreements of the people" y los levellers: la lucha por un nuevo modelo político en la Inglaterra de mediados del siglo XVII, en Historia Constitucional (revista electrónica), n. 9, 2008. http://hc.rediris.es/09/index.html

27 En este documento, de efímera vigencia (rigió solo cuatro años) aparecerán delimitados las funciones de cada uno de los órganos de gobierno y se resguardarán los derechos fundamentales del pueblo del Inglaterra, Escocia e Irlanda.
} 
oportunidad de afirmar que el mismo tuvo como una de sus principales preocupaciones la defensa de la libertad del hombre frente a las formas de organización política propias del absolutismo. Los textos constitucionales de esta etapa se propusieron proteger los "derechos individuales" frente a un Estado que se comprometía a no violarlos, a no impedir su goce, ni a interferir en el ejercicio de los mismos. Las "constituciones liberales" organizaron "Estados liberales", diseñados para abstenerse de intervenir en las relaciones económicas-sociales (Estados gendarmes). ${ }^{28}$

Las primeras constituciones que respondieron a las características antes señaladas, con valor positivo, plena vigencia y eficacia, serán las que se dieron las colonias inglesas radicadas en el Norte de América durante el movimiento emancipador que concluyó con la declaración de independencia de $1776 .{ }^{29}$

La Constitución de los Estados Unidos será sancionada en 1787 en la ciudad de Filadelfia, entrando en vigencia el año siguiente al contar con la necesaria ratificación de un mínimo de nueve estados para que tuviese vigor. Durante ese breve tiempo se publicará "El Federalista", un compendio de varios artículos de opinión favorables a la ratificación del nuevo texto constitucional. Se trata de una obra clásica en la materia y de enorme difusión cuya autoría pertenece a Hamilton, Madison y Jay. ${ }^{30}$

La constitución norteamericana se componía de tan solo siete artículos y no contaba con una declaración de derechos. (omisión suplida luego con las primeras enmiendas sancionadas en 1789$)^{31}$. El valor de este texto constitucional es innegable,

28 MORENO, Guillermo Raúl, Textos Completos de la Constitución Nacional y de la Provincia de Buenos Aires de 1949, $1^{\text {a }}$ edición, La Plata, Edulp, 2005, 100 p., ISBN 950-34-0345-6, p. 11.

29 Para la exposición de este punto referido al constitucionalismo surgido de la revolución norteamericana, acudimos en ayuda a la obra de Linares Quintana, quien ha desarrollado una profunda investigación sobre el tema. LINARES QUINTANA, Segundo V., Tratado de la Ciencia del Derecho Constitucional, $2^{a}$ edición, Buenos Aires, 1977,462 p., Editorial Plus Ultra, T 1, p. 78.

30 HAMILTON, Alexander; MADISON, James y JAY, John, El Federalista, http://libertad.org/ media/El-Federalista.pdf

31 Señala Montes de Oca que “...en la Constitución de los Estados Unidos, tal como la sancionó la Convención de 1787 y fue ratificada por los diversos Estados de la Unión, no 
a tal punto que será modelo a seguir por muchos países del mundo, entre ellos, el nuestro.

Por su parte, la revolución francesa de 1789, hecho histórico sobresaliente en la historia occidental, generó un cambio abrupto y profundo en la Francia de entonces, pero sus efectos tuvieron una proyección universal ${ }^{32}$. El derrumbe aristocrático se hizo realidad, pues la revolución francesa rompió de manera violenta con el "antiguo régimen".

La crítica situación económica, sumada a la debilidad del monarca Luis XVI, desembocaron en la convocatoria a los Estados Generales (equivalentes al parlamento) ausentes desde 1614. Allí estaban representados los tres sectores que componían la población: el clero, la nobleza y el estado llano (o tercer estado). A partir de ese momento, la agitación, el estallido y la extrema violencia se apoderaron de Francia. Bandas armadas tomaron por asalto la prisión oficial donde se alojaban detenidos sin proceso, llamada la Bastilla, símbolo del poder real. ${ }^{33}$

Los diputados de los comunes, el "tercer estado", se autoproclamó Asamblea Nacional Constituyente dictando la primera Constitución de Francia en 1791. La monarquía quedó abolida y el Rey Luis XVI es ejecutado en la guillotina en 1793.

Entre tanto, la Asamblea había aprobado la "Declaración de los Derechos del Hombre y del Ciudadano" en 1789, como expresión más genuina del pensamiento ideológico de la revolución. En él se condensaron los derechos fundamentales

existía un Bill, y fue éste, precisamente, uno de los vicios más serios y más graves que los opositores al régimen que se creaba hicieron notar en la obra de la convención”. MONTES DE OCA, M.A., Lecciones de Derecho Constitucional, Buenos Aires, 1917, 504 p., TipoLitografía "La Buenos Aires", TI, p. 53.

32 A tal punto fue esto así, que como señala Hobsbawm, "Si la economía del mundo del siglo XIX se formó principalmente bajo la influencia de la Revolución industrial inglesa, su política e ideología se formaron principalmente bajo la influencia de la Revolución francesa. HOBSBAWM, Eric, La Era de la Revolución. 1789-1848, 6ª edición, Buenos Aires, Grupo Editorial Plantea, 2007, 344 p., ISBN 978-987-9317-14-3, p. 61.

33 Ver en BIDART CAMPOS, Germán, Manual de Historia Política, $1^{\text {a }}$ reimpresión, Buenos Aires, Ediar, 1997, 345 p., ISBN 950-574-100-6, p.230. 
del hombre, cualquiera sea su condición, edad o nacionalidad. ${ }^{34}$ Este documento, que tendrá una amplia difusión en el mundo entero, bien podría ser la parte orgánica de cualquier constitución. ${ }^{35}$ Compartimos la opinión de considerarla como la más importante de las declaraciones de derechos básicos, por lo menos hasta la de las Naciones Unidas de 1948, que se inspira en aquella. De hecho, ha sido tomada como modelo por la mayoría de las declaraciones posteriores hasta la actualidad. ${ }^{36}$

\section{3) Difusión del constitucionalismo liberal}

La creencia en una constitución escrita como garantía de la libertad e instrumento de limitación al poder estatal, rápidamente se proyectó por todas las naciones del mundo a partir de los modelos de los Estados Unidos de Norteamérica y de Francia. De esa forma el constitucionalismo liberal entró en su etapa de difusión durante todo el siglo XIX.

Como ejemplo de este período se pueden mencionar: la Constitución de Cádiz, España, (1812); Noruega (1812); Bélgica (1831); Chile (1813), Perú (1823); Uruguay (1830), entre tantas otras.

La Constitución argentina sancionada por el Congreso de Santa Fe en 1853 también debe ser incluida en este período de difusión del constitucionalismo liberal. Su demora en ver la luz encuentra su fundamento en las luchas internas, protagonizadas por unitarios y federales, quienes pugnaron por imponer la forma de organización institucional.

\footnotetext{
34 Comienza estableciendo en su primer artículo que "los hombres nacen libres e iguales en derechos...".

35 En ese sentido se pronuncia SANGUINETTI, Horacio, en Historia de las ideas políticas universales y argentinas, Buenos Aires, Cooperadora de Derecho y Ciencias Sociales, 1977, 308 p., p.131.

36 Ver RABINOVICH-BERKMAN, Ricardo D., Manual de Historia del Derecho, $1^{\text {a }}$ edición, Buenos Aires, Bogotá, Puerto Alegre, Astrea, 2016, 496 p., ISBN 978-987-706-130-7, p. 429.
} 


\section{4) Crisis del constitucionalismo liberal}

Esta etapa del proceso histórico que hemos denominado constitucionalismo transcurre en la primera mitad del siglo $\mathrm{XX}$, fundamentalmente entre la primera y la segunda guerra mundial. En efecto, durante ese período surgieron regímenes totalitarios en algunos países de Europa que significaron un verdadero retroceso en los principios y postulados del constitucionalismo.

En este momento de involución del constitucionalismo, al que también se lo suele denominar período de "desconstitucionalización", aparecieron tendencias totalitarias y dictaduras de partidos negatorias de aquellos postulados elementales del derecho constitucional. Claro ejemplo de estas tendencias fueron la revolución rusa de 1917 (con el acceso del comunismo al poder); el advenimiento del "fascismo" con Benito Mussolini en Italia (1922); el "nacional-socialismo" en la Alemania de Adolf Hitler (1933), el "falangismo" español en cabeza del General Francisco Franco (1939) y el Estado totalitario portugués iniciado por la dictadura de Oliveira Salazar (1926).

\section{5) Constitucionalismo social}

Identificamos al "constitucionalismo social" con aquella etapa dentro del proceso histórico en el cual fueron incorporadas cláusulas de contenido económico y social en las leyes fundamentales de los estados.

El constitucionalismo social no derogó las conquistas obtenidas por el constitucionalismo liberal, por el contrario, vino a complementarlo con una mirada más humanitaria, haciendo foco en el hombre como ser vulnerable ante contingencias que muchas veces a lo largo de su vida se ve en la necesidad de enfrentar (necesidad de vivienda; condiciones dignas de trabajo; previsión social; acceso a la salud; alimentación adecuada; etc.) o como miembro de grupos desaventajados que requieren una tutela especial por parte del Estado (niños; ancianos; enfermos; discapacitados; etc.). Así, los derechos individuales, 
consagrados por el constitucionalismo liberal, se vieron complementados por los derechos de contenido social.

Al hablar de los orígenes del constitucionalismo social, no podemos dejar de mencionar la incidencia que tuvo en su génesis y evolución la llamada "doctrina social de la iglesia". La agudización de las consecuencias sociales de la revolución industrial se hicieron sentir en el Siglo XIX. Así, el proceso de industrialización, sumado a la veneración de la ideología liberal, comenzó a hacer estragos en la población más excluida: migraciones masivas del campo a la ciudad; concentraciones en centros urbanos en rededor de las fábricas, deficiencias sanitarias y habitacionales; condiciones indignas de trabajo; hacinamiento, crisis económicas, etc. De esta forma, la "cuestión social" pasó a ser una de las grandes preocupaciones de la Iglesia Católica, y dentro de sus filas se alzaron voces reclamando cambios en las condiciones de los más necesitados.

En este contexto aparecieron numerosos documentos pontificios referidos a temas políticos y sociales, mereciéndose destacar la encíclica Rerum Novarum ${ }^{37}$ del Papa León XIII, dada a conocer en $1891^{38}$. En ella se expuso la preocupante situación de los obreros y la necesidad de la intervención estatal en protección de los trabajadores, niños y mujeres.

Las primeras expresiones del constitucionalismo social surgirán en los inicios del Siglo XX con la sanción de la Constitución de México de $1917^{39}$ y la Constitución de Weimar (Alemania) en 1919.

\footnotetext{
37 Del latín "cosas nuevas".

38 Cuarenta años después, en 1931, el papa Pío XI conmemoró aquel acontecimiento con su encíclica Quadragesimo anno, continuando y profundizando la doctrina iniciada por León XIII. Otras encíclicas seguirán luego con el camino iniciado en esta doctrina: Mater et magistra, de Juan XXIII (1961); centesimus annus, de Juan Pablo II (1991), entre otras.
}

39 Como señala el maestro Bonavides, el constitucionalismo social tendrá su certificado de nacimiento en el campo de la positividad a partir de la promulgación de la carta magna de México, de 1917. BONAVIDES, Paulo, El carácter pionero de la Constitución de México de 1917, Revista Derechos en Acción, Año 3/No 8 Invierno 2018, 587-599. 
Resulta necesario destacar que estas constituciones, como otras que luego seguirán el mismo camino, no hicieron más que jerarquizar los derechos sociales que ya existían a nivel infraconstitucional. Es decir, en esta etapa son ubicados en la cúspide del ordenamiento jurídico (la propia Constitución) derechos con contenido económico-social ya vigentes en legislaciones inferiores. ${ }^{40}$

En nuestro país, las primeras apariciones de cláusulas constitucionales con contenido social se harán efectivas en el Derecho Público Provincial (San Juan 1927; Entre Ríos 1933, Santiago del Estero 1939, etc.)

En el orden federal, toda vez que la Constitución de 1853 se adscribe al constitucionalismo liberal ${ }^{41}$, no contó con este tipo de disposiciones (tampoco fueron incorporadas en sus posteriores reformas) hasta 1949, año en que la ley fundamental experimentó una profunda trasformación en materia económica y social durante el primer gobierno del General Juan Domingo Perón.

\section{6) Constitucionalismo actual}

El nacimiento del constitucionalismo liberal a fines del siglo XVIII, y su expansión al mundo entero durante el siglo XIX, dio inicio a la lucha por la protección de los derechos civiles y políticos frente a posibles arbitrariedades de las autoridades públicas. Se trata de los denominados derechos de "primera generación". (distintos tipos de libertades: de expresión, de entrar, permanecer, circular y salir del territorio, de religión, de peticionar a las autoridades, de ejercer toda industria lícita, de usar y disponer de la propiedad privada, etc.).

\footnotetext{
40 En similares términos se pronuncia el Profesor Vanossi, a quien recurrimos para el desarrollo de esta temática. VANOSSI, Jorge Reinaldo, El Estado de Derecho en el Constitucionalismo Social, Buenos Aires, Eudeba, 1982, 398 p., ISBN 950-0020-3.

41 Su adhesión a las doctrinas liberales es clara e inequívoca: Preámbulo ("asegurar los beneficios de la libertad") y arts. 14,17,20,25,26,27,31 y concordantes de la parte orgánica. Como señala Durante, "Particularmente, cabe destacar el derecho de propiedad individual, verdadero paradigma de la noción liberal de la libertad". DURANTE, Alfredo, La Constitución Real. Enfoques Multidisciplinarios. Cap. I, Orden Socioeconómico y Derecho Constitucional, L. La Ley, Buenos Aires, 2001, p. 9.
} 
Luego el constitucionalismo social, con una visión menos individualista, puso atención en los grupos vulnerables de la sociedad y en sus necesidades más elementales. Surgieron así los "derechos de segunda generación", de clara naturaleza económica, social y cultural.

El constitucionalismo actual se nos presenta como un proceso que enfoca no solo al hombre en su individualidad (derechos personales o de primera generación) o en su dimensión social (derechos sociales o de segunda generación), sino que además se plantea nuevos desafíos vinculados con una visión universal, teniendo en cuenta no solo a quienes hoy habitamos este planeta, sino a las generaciones que nos sucederán. Así adquieren relevancia las normas incorporadas a las constituciones que procuran tutelar el medio ambiente, los recursos naturales, la paz a escala planetaria; la manipulación genética; los derechos de usuarios y consumidores, etc. Serán los "derechos de tercera generación", derechos difusos o de incidencia colectiva.

\section{Poder Constituyente y Poderes Constituidos. Constitución, concepto. Tipologías}

\section{IV.1. Poder constituyente y poderes constituidos}

Toda Constitución tiene un acto de creación, de nacimiento. Será el pueblo, titular de la soberanía, quien lleve adelante este acto inicial tendiente a organizar el poder político y dejar establecidos sus derechos fundamentales.

La teoría del poder constituyente fue elaborada en tiempos de la Revolución francesa de finales del Siglo XVIII. Se adjudica al abate Sieyès la paternidad de dicha teoría, desde el momento que fuera expuesta en su célebre ensayo "¿Que es el tercer Estado?" publicado en $1789^{42}$. Allí identificó al poder constituyente con

42 Sieyès, uno de los más importantes pensadores de la revolución francesa, comienza su obra con tres sencillas preguntas: “¿ué es el tercer estado? Todo. 2. ¿Qué ha sido hasta 
una fuerza política que "crea" la Constitución de un Estado en una instancia racional, voluntaria y deliberativa. ${ }^{43}$

En razón de lo expuesto, podemos definir al poder constituyente, en líneas generales, como la capacidad o potestad con que cuenta el pueblo para dictar una Constitución, o modificar una ya vigente. ${ }^{44}$

Como señala el Profesor Sagües, al referirse al tema que estamos tratando, la expresión "poder constituyente" tiene un doble carácter, ya que refiere tanto a la facultad o potencia para establecer y alterar la Constitución (poder- función) como a quien lo hace (poder-persona). El establecimiento de la Constitución comprende tanto a su sanción (elaboración y aprobación) como a su promulgación (acto de mandarla a ejecutar, ponerla en vigencia y publicarla). ${ }^{45}$

El Poder constituyente puede ser "originario" o "derivado". El poder constituyente "originario" es aquella potestad suprema que tiene el pueblo para dictarse su primera constitución,

el presente en el orden político? Nada. 3. ¿Cuáles son sus exigencias? Llegar a ser algo". SIEYÈS, Emmanuel-Joseph, ¿Qué es el Tercer Estado", 1789, Biblioteca Omegalfa, 2019.

43 Ver MURUA, Ignacio Colombo, Límites a las reformas constitucionales. Teoría de las cláusulas pétreas., $1^{\text {a }}$ edición, Buenos Aires, Astrea, 2011, 288 p., ISBN 978-950-508-936-9, p. 114. 44 Según el maestro Bidart Campos, sería la "competencia, capacidad o energía para constituir o dar constitución al estado, es decir, para organizarlo, para establecer su estructura jurídico-política". BIDART CAMPOS, Germán, Manual de la Constitución Reformada, $4^{\mathrm{a}}$ reimpresión, Buenos Aires, Ediar, 2005, 568 p., ISBN 950-574-111-1, T I, p.373. Por su parte, Juan Vicente Sola se pregunta: ¿Cuál es el fundamento de la Constitución?, ¿Quién puede crear normas constitucionales?... La legitimidad de una constitución supone una conformidad necesaria y sustancial con los intereses aspiraciones y valores de una sociedad en determinado momento de su historia. De esta manera una Constitución no representa una simple legitimación del poder están bien hacer positivos ciertos valores jurídicos." SOLA, Juan Vicente, Tratado de Derecho Constitucional, $1^{\text {a }}$ edición, Buenos Aires, LA LEY, 2009, 848 p., ISBN 978-987-03-1449-3, T I, p. 223. Según Carl Schimit, una Constitución puede tener nacimiento de dos maneras distintas: mediante una decisión política unilateral del sujeto del Poder constituyente o mediante convención plurilateral de varios de tales sujetos (surgirá entonces una constitución pactada o convenida). Ver SCHIMT, Carl, Teoría de la Constitución, Madrid, Editorial Revista de Derecho Privado, 1934, 457 p., p. 50.

45 SAGÜES, Néstor Pedro, Manual de Derecho Constitucional, $2^{\text {a }}$ edición, $1^{\text {a }}$ reimpresión, Buenos Aires, Astrea, 2014, 936 p., ISBN 978-950-508-966-6, p. 54. 
de allí que también se lo conozca como poder constituyente "fundacional". Por su parte, será poder constituyente "derivado" aquel ejercitado para reformar o modificar una constitución ya existente, por tal motivo es usual que también se lo llame poder constituyente "reformador".

Asimismo, en Estados federales como el nuestro, se pueden diferenciar el poder constituyente "federal" (o de primer grado) y el poder constituyente "provincial" ${ }^{46}$ (o de segundo grado). ${ }^{47}$

Las provincias argentinas son Estados que conforman una unión federal, y es por ello, que, en ejercicio de la autonomía que detentan, pueden dictarse sus propias constituciones. Es más, según el artículo 5 de la Constitución Nacional tienen la obligación de hacerlo, pues allí el constituyente dejó establecido que "cada provincia dictará para sí una Constitución...".

Debemos señalar que el poder constituyente provincial, sea originario o derivado, tendrá limitaciones impuestas por la propia Constitución Nacional, ya que por el principio de supremacía constitucional no podrían contradecirlas en sus aspectos centrales. Las provincias en sus respectivas constituciones deberán asegurar el sistema representativo republicano, de "acuerdo con los principios, declaraciones y garantías de la Constitución Nacional", debiendo asegurar la "administración de justicia, su régimen municipal y la educación primaria” (art. 5 C.N.).

Uno de los principios básicos surgidos del constitucionalismo clásico o liberal fue la distinción entre "poder constituyente" y

\footnotetext{
46 Ampliar en HERNANDEZ, Antonio M., El Poder Constituyente en las Provincias en Derecho Público Provincial, $1^{\text {a }}$ edición, Buenos Aires, LexisNexis, 2008, cap. V, p. 155-184, ISBN 978987-592-318-8.

47 También se podría mencionar la existencia de un poder constituyente municipal o de "tercer grado". En este sentido señala Atela que: "El poder constituyente municipal puede describirse como una fuerza creadora de la voluntad social para organizarse política y jurídicamente, estableciendo cómo se han de establecer los poderes constituidos del estado municipal, determinando sus límites y organización, así como la definición de la materia local (competencia municipal)". ATELA, Vicente Santos y CAPutTO, Juan Manuel, Poder constituyente municipal y cartas orgánicas, $1^{\text {a }}$ edición, La Plata, Facultad de Ciencias Jurídicas y Sociales de la UNLP, 2008, 290 p., ISBN 978-950-34-1587- 0, p.16.
} 
"poderes constituidos". Estos últimos resultan ser una creación del poder constituyente, por lo tanto, se encuentran en una grada jerárquica inferior que aquel. Los identificamos con los órganos de poder creados y reglamentados en el texto constitucional. Así, los poderes constituidos solo tendrán las atribuciones y competencias delimitadas por la Constitución. En nuestro sistema institucional, son poderes constituidos: el Poder Ejecutivo, el Poder Legislativo y el Poder Judicial.

\section{IV.2. Constitución}

La palabra "constitución" es utilizada desde tiempos muy antiguos, pero con distintos sentidos. Por esta razón, nos resultaría imposible reunir en un solo concepto la totalidad de sus posibles significados que ha tenido a lo largo de los años. No obstante, como bien se ha señalado, todas las acepciones del término giran en rededor del poder político y del aparato que se sirve de él, el Estado. ${ }^{48}$

Cuando se afirma, en un sentido llano, que un país está "constituido" de tal o cual manera, no se hace más que hacer una descripción de su realidad. Es como si dijéramos que el aire que respiramos está "constituido" básicamente por dos elementos: el nitrógeno y el oxígeno. Desde esta perspectiva, la constitución es el conjunto de caracteres específicos de algo ${ }^{49}$, es decir la esencia o cualidad de una cosa que la "constituye" como es, y por lo tanto, la diferencia de las demás.

La afirmación "todo Estado precisa una constitución" es verdadera, porque toda asociación permanente de hombres, para que fuese tal, requiere un principio de ordenación conforme el cual se constituya y desenvuelva su voluntad..$^{50}$ Entonces, al

\footnotetext{
48 EKMEKDJIAN, Miguel Ángel, Tratado de Derecho Constitucional, $2^{\text {a }}$ edición, Buenos Aires, Depalma, 2000, 712 p., ISBN 950-14-1746-8, T. I, p. 43.

49 Definición prevista en el Diccionario de la Real Academia Española.

50 JELLINEK, Georg, Teoría del Estado, México D.F., Oxford University Press, 1998 ,p. 302, citado por FERREYRA, Raúl Gustavo, op. cit., p. 190.
} 
referirnos en estos términos, hacemos alusión a la "constitución fáctica", "real" o "material", la que responderá a la realidad social, política, económica de un pueblo determinado.

En otro sentido, nos apunta Emekdjian, el vocablo "constitución”, designa a un conjunto de normas jurídicas que regulan y determinan el modo en que debe ser ejercido el poder político. En otras palabras, establecen como debe ser la estructura del Estado. Ésta es la llamada por diversos autores, la constitución formal, normativa, política o simplemente "constitución" sin ningún aditamento. ${ }^{51}$

Con el advenimiento de las revoluciones de finales del Siglo XVIII surgirán las primeras constituciones escritas, codificadas y rígidas, que, además de organizar la estructura y funcionamiento de los poderes, incluirán declaraciones, derechos y garantías. Antes de este momento histórico, no podemos decir que existieron "constituciones" en el sentido que actualmente le otorgamos.

Pasaron muchísimas generaciones para que el hombre aprendiera que solo se podrían garantizar sus derechos individuales si existían límites a los detentadores del poder, y que esos frenos que la sociedad deseaba imponer a los gobernantes deberían plasmarse en un sistema de normas fijas: la Constitución. ${ }^{52}$

Hechas todas estas aclaraciones previas, ahora si podemos aventurarnos en una suerte de definición:

La "Constitución" es la norma suprema de un Estado por medio de la cual se reglamenta el ejercicio de todo el poder político y se reconoce los derechos fundamentales de sus habitantes. Será el cimiento sobre el cual se base todo el ordenamiento jurídico.

\section{IV.3. Tipologías de Constitución}

La doctrina constitucional ha llevado adelante la tarea de clasificar a las constituciones de acuerdos a sus características

\footnotetext{
51 EKMEKDJIAN, Miguel Ángel, op. Cit., p. 44.

52 Ver el desarrollo sobre el tema en LOEWENSTEIN, Karl, Teoría de la Constitución, $3^{\mathrm{a}}$ reimpresión, Barcelona, Editorial Ariel, 1983, 619 p., ISBN 84-344-1972-8, p. 149.
} 
particulares, agrupándolas en diversas clasificaciones o tipologías.

Una Constitución podrá ser escrita o no escrita, incluso puede ser parcialmente escrita (como el caso del Reino Unido y de Nueva Zelanda, donde coexisten leyes constitucionales emitidas por el Parlamento con costumbres constitucionales que también tienen fuerza obligatoria) ${ }^{53}$

Teniendo en cuenta los procedimientos para ser reformada, una constitución podrá ser: rígida, flexible o pétrea.

Será rígida aquella constitución que para ser reformada necesite acudir a procedimientos especiales, diferentes a los trámites ordinarios para la formación y sanción de leyes. De esta forma, se persigue una mayor dificultad para modificar el texto constitucional exigiendo mayorías especiales o la convocatoria a órganos diferentes para tal cometido. Pues, como señala Sánchez Viamonte, toda reforma constitucional es un acontecimiento de trascendencia indudable.$^{54}$ Por su parte, una constitución será flexible cuando se pueda reformar a través del mismo procedimiento utilizado para la sanción de leyes ordinarias. Por último, las constituciones pétreas (derivación de la palabra "piedra" o "roca") serían aquellas en las cuales estaría vedada una reforma, es decir, las "irreformables" o "eternas". Estas clases de constituciones se limitan en la actualidad a una categoría teórica o académica, inexistente en el plano de la realidad. Pues si bien las constituciones pretenden durar en el tiempo, jamás se podría pensar en una Ley Suprema que nunca se modifique desconociendo la lógica evolución de toda sociedad.

Si nos atenemos a la clasificación mencionada, nuestra Constitución Nacional la debemos ubicar dentro de las catalogadas cómo rígidas. Ello es así, toda vez que para su

\footnotetext{
53 EKMEKDJIAN, Miguel Ángel, op. Cit. P. 52.

54 SANCHEZ VIAMONTE, Carlos, Manual de Derecho Constitucional, $4^{\text {a }}$ edición, Buenos Aires, Editorial Kapeluz, 1959, 413 p. p. 347.
} 
modificación deben ser utilizados procedimientos distintos a los previstos para la sanción de leyes comunes. En su artículo 30 establece que "La Constitución puede reformarse en el todo o en cualquiera de sus partes. La necesidad de reforma debe ser declarada por el Congreso con el voto de dos terceras partes, al menos, de sus miembros; pero no se efectuará sino por una convención convocada al efecto".

Como se puede advertir de la lectura del mencionado artículo 30, la Constitución solo puede ser reformada por un órgano distinto al Congreso de la Nación, se trata de una convención nacional constituyente, la que debe ser convocada para esos efectos y se integrará por ciudadanos elegidos por el cuerpo electoral. Además, se estableció que será el Parlamento Nacional quien deba declarar la necesidad de la reforma, siempre que se cuente con suficiente consenso político para ello (se exige una mayoría calificada de las dos terceras partes de la totalidad de los legisladores que integren las Cámaras del Congreso).

Además, podríamos afirmar que en nuestra constitución formal no existen cláusulas pétreas, pues quedó establecido que la Constitución puede reformarse en "todo o en cualquiera de sus partes". 55

También resulta conocida la tipología efectuada por Lasalle en un ciclo de disertaciones llevadas a cabo en Berlín en el año 1862, las que luego dieron lugar a una conocida obra titulada “QQué es una Constitución?”. Allí, Lasalle diferenciaba la "constitución formal" (escrita), a la que el jurista alemán denominaba "tira de papel" y la "constitución real", asociada a los factores efectivos de poder. Al inicio de sus conferencias preguntó a su auditorio: que ocurriría, si por caso (muy improbable, por cierto), se quemaran todas las constituciones del país. Pues

\footnotetext{
55 Ampliar en el capítulo de la obra del Prof. Quiroga Lavié: ¿Cómo se reforma la Constitución argentina?", QUIROGA LAVIÉ, Humberto, Lecciones de Derecho Constitucional, Buenos Aires, Depalma, 1995, p. 41.
} 
en lo concreto nada pasaría al día siguiente, pues los factores reales y efectivos de poder seguirían siendo los mismos. ${ }^{56}$

\section{Supremacía constitucional y Estado Federal. Sistemas de control de constitucionalidad}

\section{V.1. Supremacía Constitucional y Estado Federal}

Desde el surgimiento del constitucionalismo liberal se tiene a la Constitución como a la "ley de leyes" 57 , es decir con carácter supralegal, será la ley suprema entre las demás, pues estará por encima de todas las normas que integren el ordenamiento jurídico positivo. ${ }^{58}$

En líneas generales podemos definir como "supremacía constitucional" al principio mediante el cual se reconoce a la Constitución el carácter de norma superior de todo el ordenamiento normativo del Estado.

El principio de supremacía de la Constitución es consecuencia natural de la estructura jerárquica del ordenamiento jurídico, pues en él conviven normas ubicadas en diferentes niveles o peldaños. Resulta oportuno, al analizar lo que estamos comentando, tener presente la teoría gradualista del ordenamiento jurídico elaborada por el maestro Hans Kelsen a principios del

56 LASALLE, Ferdinand, ¿Qué es una Constitución?, 2ª edición, Barcelona, Ariel Derecho, 2002, 183 p., ISBN 84-344-3216-1, p. 84.

57 Al referirse a este tema, Alberdi, el gran ideólogo de la Constitución nacional sostenía que: Fuera de la Constitución no existe, ni puede, ni debe existir ley alguna que de algún modo no sea reglamentaria de los principios, derechos y garantías privados y públicos, que la dicha Constitución establece como base fundamental de toda ley en la República. Según esto, todas las leyes del derecho civil, comercial y penal, todos los reglamentos de la administración en sus diferentes ramos de gobierno, guerra, hacienda, marina, etc., no son más que leyes y decretos orgánicos destinados a poner en ejercicio los derechos del Estado y de sus habitantes, consagrados expresamente por la ley fundamental de, las otras leyes. ALBERDI, Juan Bautista, Sistema Económico y Rentístico de la Confederación Argentina, versión digital en http://www.hacer.org/pdf/sistema.pdf p. 39

58 BIDEGAIN, Carlos María, Curso de Derecho Constitucional, $2^{\text {a }}$ edición, Buenos Aires, LexisNexis Abeledo-Perrot, 2005, 174 p., ISBN 950-20-1657-2.,TI, p.27. 
Siglo XX. La misma se encuentra representada en su famosa "pirámide jurídica", en cuyo vértice superior se encuentra la norma fundamental que otorga validez a todo el ordenamiento jurídico. ${ }^{59}$

Resulta habitual encontrar en las propias constituciones alguna cláusula que consagre expresamente el principio de supremacía mencionado. En nuestra Ley Fundamental, por caso, la hallamos en su artículo 31cuando establece que "Esta Constitución, las leyes de la Nación que en su consecuencia se dicten por el Congreso y los tratados con las potencias extranjeras son la ley suprema de la Nación; y las autoridades de cada provincia están obligadas a conformarse a ella, no obstante cualquiera disposición en contrario que contengan las leyes o Constituciones provinciales..."

Por último, debemos señalar que en los Estados de organización federal, como lo es el nuestro, existe una supremacía del derecho federal (Constitución Nacional, leyes de la Nación y tratados internacionales) sobre el derecho creado por las provincias, ello conforme las disposiciones contenidas en los artículos 5, 31 y 128 de la Constitución Nacional.

\section{V.2. Sistemas de control de constitucionalidad}

El principio de supremacía constitucional, analizado en el apartado anterior, necesariamente tendrá que contar con algún mecanismo que lo haga efectivo. Pues, para que aquel principio no se torne solamente en una mera expresión de deseos, deberá contar con instrumentos que - a modo de guardianes de

\footnotetext{
59 El destacado jurista, formado en la Universidad de Viena, sostenía que: “Un orden jurídico no es un sistema de normas yuxtapuestas y coordinadas. Hay una estructura jerárquica y sus normas se distribuyen en diversos estratos superpuestos. La unidad del orden reside en el hecho de que la creación, y por consecuencia la validez, de una norma está determinada por otra norma cuya creación a su vez ha sido determinada por una tercera norma. Podemos de este modo remontarnos hasta la norma fundamental de la cual depende la validez del orden jurídico en su conjunto." KELSEN, Hans, Teoría Pura del Derecho, $4^{a}$ edición, Buenos Aires, Eudeba, 2010, 224p., ISBN 978-950-23-0886-9, p. 118.
} 
la constitución - protejan a la Ley Fundamental ante posibles ataques de normas inferiores. ${ }^{60}$

Ahora bien, del carácter supremo de la Constitución se desprende lógicamente la invalidez de cualquier acto contrario a sus disposiciones, el que, por esa razón, pasará a ser "anticonstitucional" o "inconstitucional".

Teniendo en cuenta el órgano encargado de efectuar aquella tarea, se han diferenciado, en líneas generales, dos sistemas de control de constitucionalidad: el político y el judicial.

Los sistemas de control político de constitucionalidad, como su enunciado lo indica, están a cargo de organismos de naturaleza política, por fuera del ámbito del poder judicial. Un ejemplo histórico de este mecanismo lo encontramos en la Constitución francesa de 1852, la que instituyó al Senado como "guardián" de la Constitución. Todas las leyes debían necesariamente ser sometidas antes de su promulgación al Senado, las que eran examinadas desde el punto de vista de su constitucionalidad. Otro caso fue el de la Constitución rusa de 1924, donde el control era esencialmente político, en manos de un Comité Central Ejecutivo de la Unión. ${ }^{61}$ Como un dato poco recordado, podemos señalar que nuestra Constitución histórica de 1853 también contenía un tipo de control político de constitucionalidad con características especiales: Las Constituciones provinciales debían ser aprobadas por el Congreso Nacional para poder entrar en vigencia ${ }^{62}$, exigencia que fue acertadamente suprimida en la reforma constitucional de $1860 .^{63}$

\footnotetext{
60 En términos más categóricos se pronuncia el Profesor Quiroga Lavié al sostener que “... si la supremacía constitucional no tiene una garantía efectiva es como si no existiera". QUIROGA LAVIE, Humberto, Constitución de la Nación argentina comentada, $4^{a}$ edición, Buenos Aires, Zavalía, 2007, 800 p., ISBN 978-950-572-753-7, p. 148.

61 LINARES QUINTANA, Segundo, Tratado de la Ciencia del Derecho Constitucional, $2^{\text {a }}$ edición, Buenos Aires, Editorial Plus Ultra, 1978, 725 p., T.III, p. 361.

62 El artículo 5 disponía que: “Cada provincia confederada dictará para sí una Constitución bajo el sistema representativo republicano, de acuerdo con los principios, declaraciones y garantías de la Constitución nacional, y que asegure su administración de justicia, su régimen municipal y la educación primaria gratuita. Las constituciones provinciales serán revisadas por
} 
Por su parte, en los sistemas de control judicial de constitucionalidad los encargados de llevar adelante aquella tarea de protección de la ley fundamental ante posibles embates de normas o actos inconstitucionales serán los magistrados judiciales. Como fiel legado del constitucionalismo norteamericano, este sistema pronto será difundido y adoptado por la mayoría de los países de América, entre ellos el nuestro. ${ }^{64}$

Se impone aclarar que lo jueces, al efectuar el control de constitucionalidad de los actos de los otros poderes del Estado, no poseen la atribución de derogar norma alguna. Ello es así, toda vez que se limitarán a cumplir sus funciones específicas de decidir una controversia o contienda aplicando el derecho positivo vigente, y en esa función, se abstendrán de aplicar una norma inferior que contradiga a una norma superior.

Por lo tanto, si en el marco de una contienda judicial, el juez considera que una ley se opone a la constitución, no la aplicará al caso concreto que está decidiendo, pero ello de ninguna manera significará que la ley quede derogada o que su decisión tenga efectos erga omnes (del latín, "efectos para todos").

A su vez, los sistemas de control judicial de constitucionalidad pueden ser concentrados o difusos dependiendo si aquel se encuentra reservado en forma exclusiva a un solo órgano judicial o a cualquier juez de la Nación.

el Congreso antes de su promulgación. Bajo estas condiciones el gobierno federal garantiza a cada provincia el goce de sus instituciones". (la cursiva me pertenece, indican las partes del artículo suprimidas en la reforma de 1860).

63 Ampliar en TRIONFETTI, Víctor, El Sistema de Control de Constitucionalidad en Argentina, en Tratado de Derecho Procesal Constitucional, Santa Fe, Rubinzal-Culzoni, 2010, Tomo I, p. 449.

64 El artículo VI, segundo apartado de la Constitución norteamericana establece: "This Constitution, and the Laws of the United States which shall be made in Pursuance thereof; and all Treaties made, or which shall be made, under the Authority of the United States, shall be the supreme Law of the Land; and the Judges in every State shall be bound thereby, any Thing in the Constitution or Laws of any state to the Contrary notwithstanding." ("Esta Constitución, y las leyes de los Estados Unidos que se expidan con arreglo a ella, y todos los tratados celebrados o que se celebren bajo la autoridad de los Estados Unidos, serán la suprema ley del país y los jueces de cada Estado estarán obligados a observarlos, a pesar de cualquier cosa en contrario que se encuentre en la Constitución o las leyes de cualquier Estado"). 
Como ejemplo de los sistemas concentrados se pueden mencionar a los "Tribunales Constitucionales", organismos especialmente creados para cumplir la función de controlar la constitucionalidad de las leyes. Este tipo de tribunales surgirán en las constituciones de principios del Siglo XX a partir del modelo austríaco. ${ }^{65}$ Luego será tomado por varios países de Europa como Alemania, Francia, España, Italia, entre otros.

Por su parte, los sistemas judiciales de control de constitucionalidad difusos son aquellos que admiten ejercer dicha función en forma descentralizada a todos los tribunales ordinarios, sin ningún tipo de distinción. Es decir, cualquier juez puede efectuar el control de constitucionalidad en el marco de la causa o juicio en el cual interviene como magistrado.

Como señala Celotto, el verdadero momento fundador de la moderna idea de la revisión de constitucionalidad se remonta, más bien a lo ocurrido en los Estados Unidos de América al inicio del siglo XIX. ${ }^{66} \mathrm{El}$ jurista italiano, con dicha afirmación, se está refiriendo al famoso caso resuelto por la Suprema Corte de Justicia norteamericana en 1803, "Marbury Vs. Madison", a partir del cual se puede afirmar que nació el control constitucional de las leyes. Pues, fue la primera declaración de inconstitucionalidad por el Poder Judicial recordada en la historia del constitucionalismo ${ }^{67}$ En dicha oportunidad quedó establecido el siguiente razonamiento: "dado que la Constitución es ley, ella debe ser interpretada y aplicada por los jueces en los casos regidos por la misma, y desde que esa ley es suprema, los jueces deben darle preferencia sobre cualquier otra ley". ${ }^{68}$

65 La Constitución de Austria de 1920, cuya autoría intelectual se le adjudica a Hans Kelsen, fue la primera en el mundo en confiar a un tribunal especial la justicia constitucional.

66 CELOTTO, Alfonso, Formas y modelos de justicia constitucional, Círculo Doxa de la ciudad de Buenos Aires, http://www.circulodoxa.org/documentos/Circulo \%20Doxa \%20- \%20 Formas \%20y \%20modelos.pdf

67 Ver los comentarios y el análisis de las circunstancias históricas que rodearon al caso "Marbury vs Madison" en MILLER, Jonathan M., GELLI, María Angélica, CAYUSO, Susana, Constitución y poder político. Jurisprudencia de la Corte Suprema y técnicas para su interpretación. $1^{a}$ edición, Buenos Aires, Astrea, 1995, 672 p., ISBN 950-508-214-2, T. I, p. 3. 
Para concluir, debemos señalar que en nuestro país el control de constitucionalidad es ejercido por el Poder Judicial y de manera difusa. Ello es así, ya que no existe un solo y único tribunal para pronunciarse sobre la constitucionalidad de las leyes, sino que todo juez, de cualquier fuero y jurisdicción, se encuentra facultado para hacerlo. ${ }^{69}$

En 1862, al sancionarse la ley nro. 27 de "organización de la justicia federal" quedó establecida la obligación de los tribunales de "sostener la observancia de la Constitución Nacional, prescindiendo, al decidir las causas, de toda disposición de cualquiera de los otros poderes nacionales, que esté en oposición con ella". ${ }^{70}$ Un año más tarde, en 1863 , mediante la Ley nro. 48 fue atribuida a la Corte Suprema de Justicia de la Nación la función de intérprete final de la Constitución Nacional.

68 Citado por YMAZ, Esteban y REY, Ricardo, El Recurso Extraordinario, $3^{\text {a }}$ edición, Buenos Aires, Abeledo-Perrot, 2000, 322 p., ISBN 950-20-1287-9, p. 18.

${ }^{69}$ El artículo 116 de nuestra Constitución Nacional establece que "Corresponde a la Corte Suprema y a los tribunales inferiores de la Nación, el conocimiento y decisión de todas las causas que versen sobre puntos regidos por la Constitución y por las leyes de la Nación...." 70 Ver art. 3 de la Ley 27 (13/10/1862). 